\title{
Report for Task 8.4: Development of Control Room Layout Recommendations
}

\author{
Robert McDonald
}

September 2016

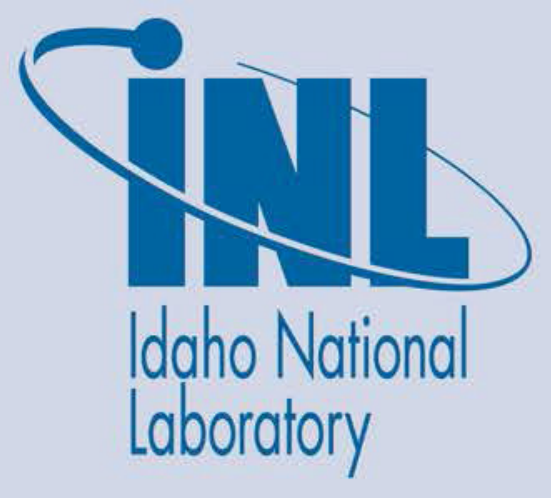

The INL is a U.S. Department of Energy National Laboratory operated by Battelle Energy Alliance 
INL/EXT-16-39800

\title{
Report for Task 8.4: Development of Control Room Layout Recommendations
}

\author{
Robert McDonald
}

September 2016

\author{
Idaho National Laboratory \\ Idaho Falls, Idaho 83415 \\ http://www.inl.gov
}

Prepared for the

U.S. Department of Energy

Office of Nuclear Energy

Under DOE Idaho Operations Office

Contract DE-AC07-05ID14517 



\section{IFE/INL-128420/08 \\ INL/EXT-16-39800}

Report for Task 8.4:

Development of Control Room

Layout Recommendations 


\begin{tabular}{|c|c|c|c|}
\hline $\begin{array}{l}\text { Address } \\
\text { Telephone } \\
\text { Telefax }\end{array}$ & 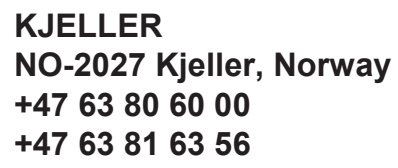 & $\begin{array}{l}\text { HALDEN } \\
\text { NO-1751 Halden, Norway } \\
\text { +4769212200 } \\
\text { +4769212201 }\end{array}$ & \\
\hline \multicolumn{3}{|c|}{$\begin{array}{l}\text { Report number } \\
\text { IFE/INL-128420/8.4 }\end{array}$} & $\begin{array}{l}\text { Date } \\
2016-09-14\end{array}$ \\
\hline $\begin{array}{l}\text { Report title an } \\
\text { Report for } \\
\text { Developm }\end{array}$ & $\begin{array}{l}\text { subtitle } \\
\text { Task 8.4: } \\
\text { nt of Control Room Layo }\end{array}$ & Recommendations & $\begin{array}{l}\text { Number of pages } \\
10\end{array}$ \\
\hline \multicolumn{4}{|c|}{$\begin{array}{l}\text { Project/Contract no. and name } \\
\text { Contract No. } 128420\end{array}$} \\
\hline \multicolumn{3}{|c|}{$\begin{array}{l}\text { Client/Sponsor Organisation and reference } \\
\text { Idaho National Laboratory, USA }\end{array}$} & \\
\hline \multicolumn{3}{|c|}{$\begin{array}{l}\text { Abstract } \\
\text { Idaho National Laboratory (INL) has contracted the Institutt for } \\
\text { Energiteknikk (IFE) to support in the development of an end state } \\
\text { vision for the US Nuclear industry and in particular for a utility } \\
\text { that is currently moving forward with a control room } \\
\text { modernization project. This support includes the development of } \\
\text { an Overview display and technical support in conducting an } \\
\text { operational study. Development of operational scenarios to be } \\
\text { conducted using a full scope simulator at the INL HSSL. } \\
\text { Additionally IFE will use the CREATE modelling tool to provide } \\
\text { 3-D views of the potential and possible end state view after the } \\
\text { completion of digital upgrade project. }\end{array}$} & \\
\hline & Name & Date & \\
\hline Author(s) & Robert McDonald & 2016-09-14 & \\
\hline Approved by & Andreas Bye & 2016-09-14 & \\
\hline
\end{tabular}




\section{Background}

Institutt for Energiteknikk (IFE) operates the OECD Halden Reactor Project (HRP) and has extensive experience from more than 20 years of research in human system interface $(\mathrm{HSI})$ design and operation of nuclear power plant research simulators in Halden Man-Machine Laboratory (HAMMLAB).

HAMMLAB serves two main purposes: the study of human behaviour in interaction with complex process systems; and the development, test and evaluation of prototype control centres and their individual systems. The aim of HAMMLAB is to extend the knowledge of human performance in complex process environments, in order to adapt new technology to the needs of the human operator. By studying operator performance in $H A M M L A B$, and integrating the knowledge gained into new designs, operational safety, reliability, efficiency and productivity can be improved.

HAMMLAB includes two nuclear power plant simulators and a modern, computerbased, highly configurable experimental control room with extensive features for studying operator crew performance. HAMMLAB's two full-scope nuclear power plant simulators, named HAMBO and GPWR, represent a Swedish BWR plant (Forsmark 3), and a typical Westinghouse 3-loop PWR plant (GSE-GPWR).

\section{Introduction}

Idaho National Laboratory (INL) has contracted IFE to support in the development of an end state vision for the US Nuclear industry and in particular for a utility that is currently moving forward with a control room modernization project. This support includes the development of an Overview display and technical support in conducting an operational study. Development of operational scenarios to be conducted using a full scope simulator at the INL Human Systems Simulation Laboratory (HSSL). Additionally IFE will use the Control Room Engineering Advanced Toolkit Environment (CREATE) modelling tool to provide 3-D views of the potential and possible end state view after the completion of digital upgrade project.

\section{Current Design}

The current nuclear control room is facing an ever present need to shift to a more digital system. This need is being felt due to obsolescence in replacement parts, technical support, and the need for more efficient control of systems to maximize the plant's capacity factor and megawatt output. The control room is the central nervous system of the plant. All major systems and components are controlled from the control boards, both safety and non-safety related. The need to upgrade older analog systems with more modern digital systems is a time consuming process that has been performed using two different methods. One method is to perform a complete plant upgrade in a 
single effort. This has been done at several sites in Europe with success but at a high cost and a loss of capacity for an extended period, typically 300 days. The current thought process is to perform this change-out over several years making system upgrades during the normal outage season thereby minimizing lost capacity factor while improving the long term reliability of the plant. This will be the process most widely used in the US based nuclear fleet and the base case which this report will be written and the processes developed.

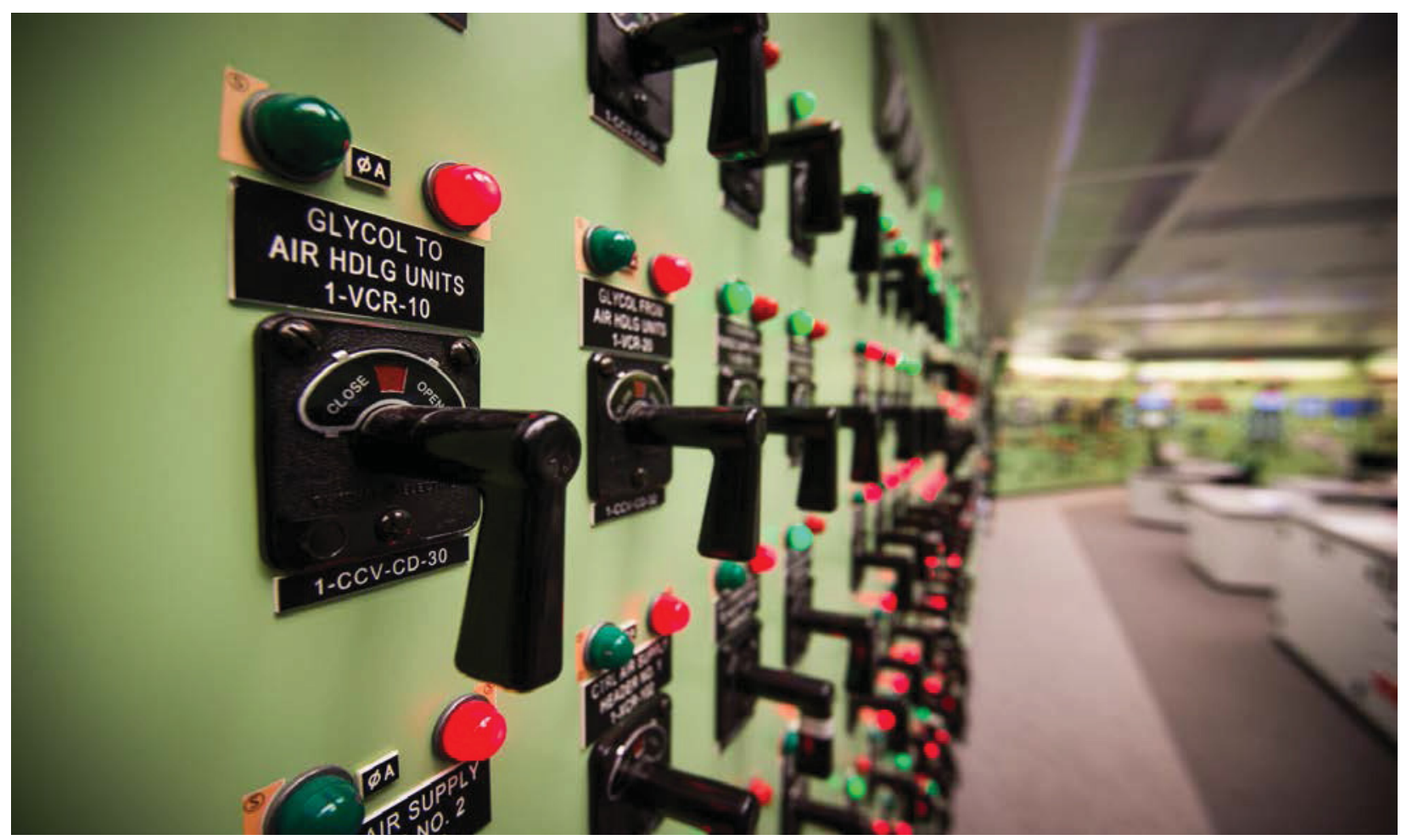

Figure 1 Example of analog control board found in many of the US Nuclear industry

\section{Control Board Changes}

The shifting to a more digitally controlled environment allows the control room operator to control more systems from a single computer display, making the control switches and board indications obsolete. The majority of the operator's action on digital systems will be performed using various displays and mouse driven controls. An effort will be made to remove the redundant instrumentation and controls to reduce the cost for maintenance and the need to maintain replacement parts. The question then becomes what to do with the new available board real estate that can support the operators in their daily work routines as well as emergency situations. Institute for Energy Technology's (IFE) solution is the development of overview displays, tasked based displays and procedure support displays that provide the operator with integrated information displays, using innovative symbols and processes. The digital upgrade of a system will determine which portion of the control board will have components removed and open up available board space. IFE can use it's CREATE process to determine 
how to best use the newly created space to place high definition monitors for use of the innovative displays. The Halden Virtual Reality Center(HVRC) Control Room

Engineering Advanced Toolkit Environment (CREATE) process will provide a 3-D model of the control room and control boards that is capable of being manipulated to provide various output designs which would best suit the plant site. CREATE supports a humancentred iterative design process and is designed for use as a support tool during the preliminary and detailed design of a new control room or a control room upgrade. The use of the CREATE tool will allow IFE to determine and identify the ideal sight lines and the minimum text and number size for the individual displays. Based on the CREATE report we then can start the development of the desired displays that can be created and projected on the newly installed monitors created by the digital upgrade.

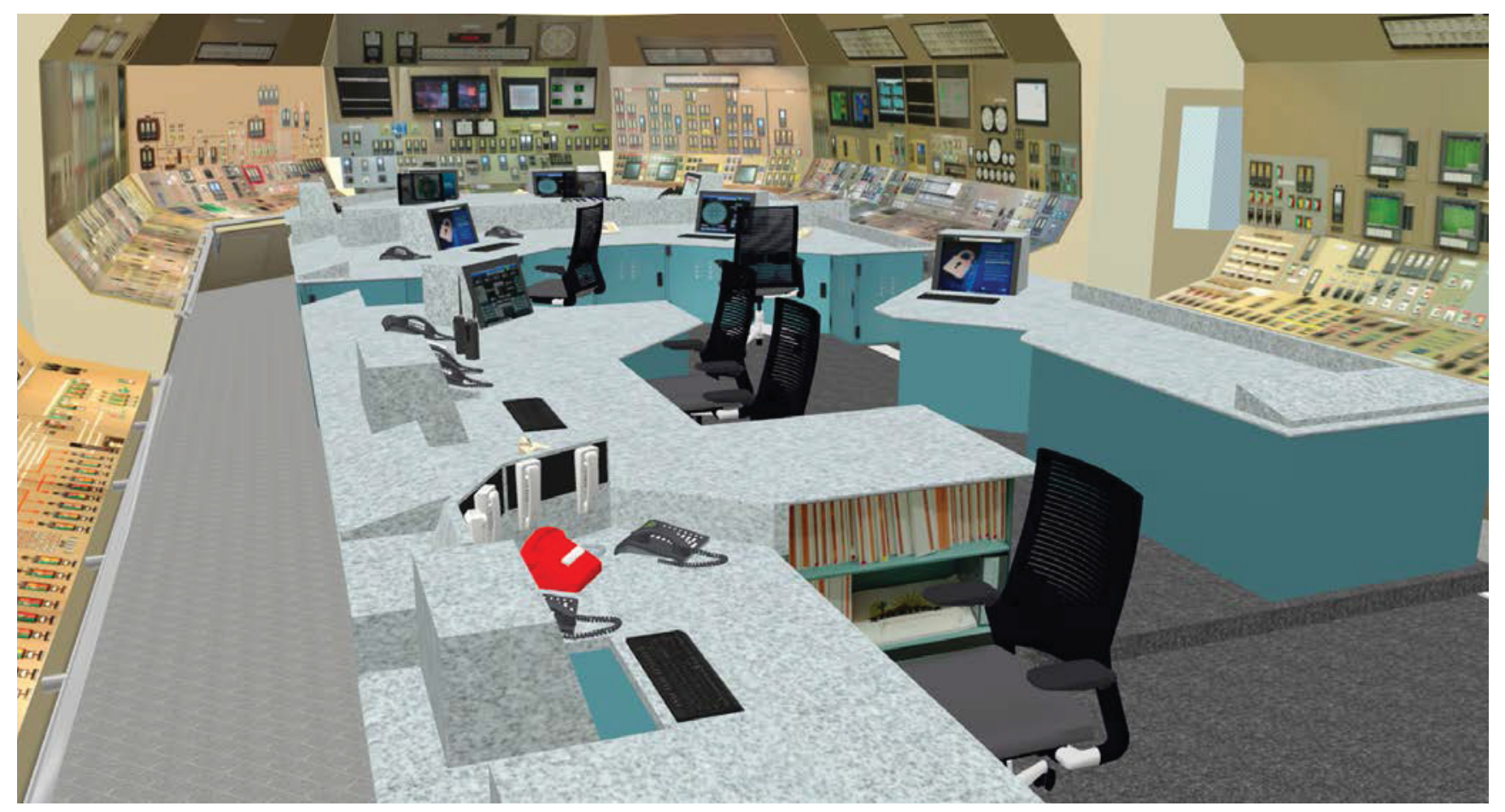

Figure 2 Example of CREATE drawing of a control room

\section{Development of Overview and Support Displays}

The development of the overview and task based displays is an iterative process that begins with the basic look and understanding of a plants design. Systems and components are identified as required for daily operation or emergency operation. The current design for the overview display is a four screen display showing the Reactor Coolant System, Emergency Core Cooling System, Turbine Systems, and Electrical Distribution. These displays use an integrated information concept developed and deployed in IFE's HAMMLAB. The use of various symbols and metrics provide the operator with a quick understanding and visual confirmation that plant system/parameters are changing. These displays use both visual cues and numerical cues. The first iteration is for the developer/designer to use previous experience and 
develop the four screens. Using past designs of similar overview displays and making adjustments for new systems and components, an initial display is developed. The next step is getting the end user involved, in this case the operations personnel. By having their direct involvement in this process it limits the potential for significant changes to the displays after completion and the simulator operational study. By closely working with the end user and Human Factors support at IFE a final overview display can be created and installed for testing and conducting an operations users study. Additional support displays can be created following the same process. These displays are based on identified need of the site and include operator inspired displays, control room supervision displays, plant management overview displays and emergency specific displays.

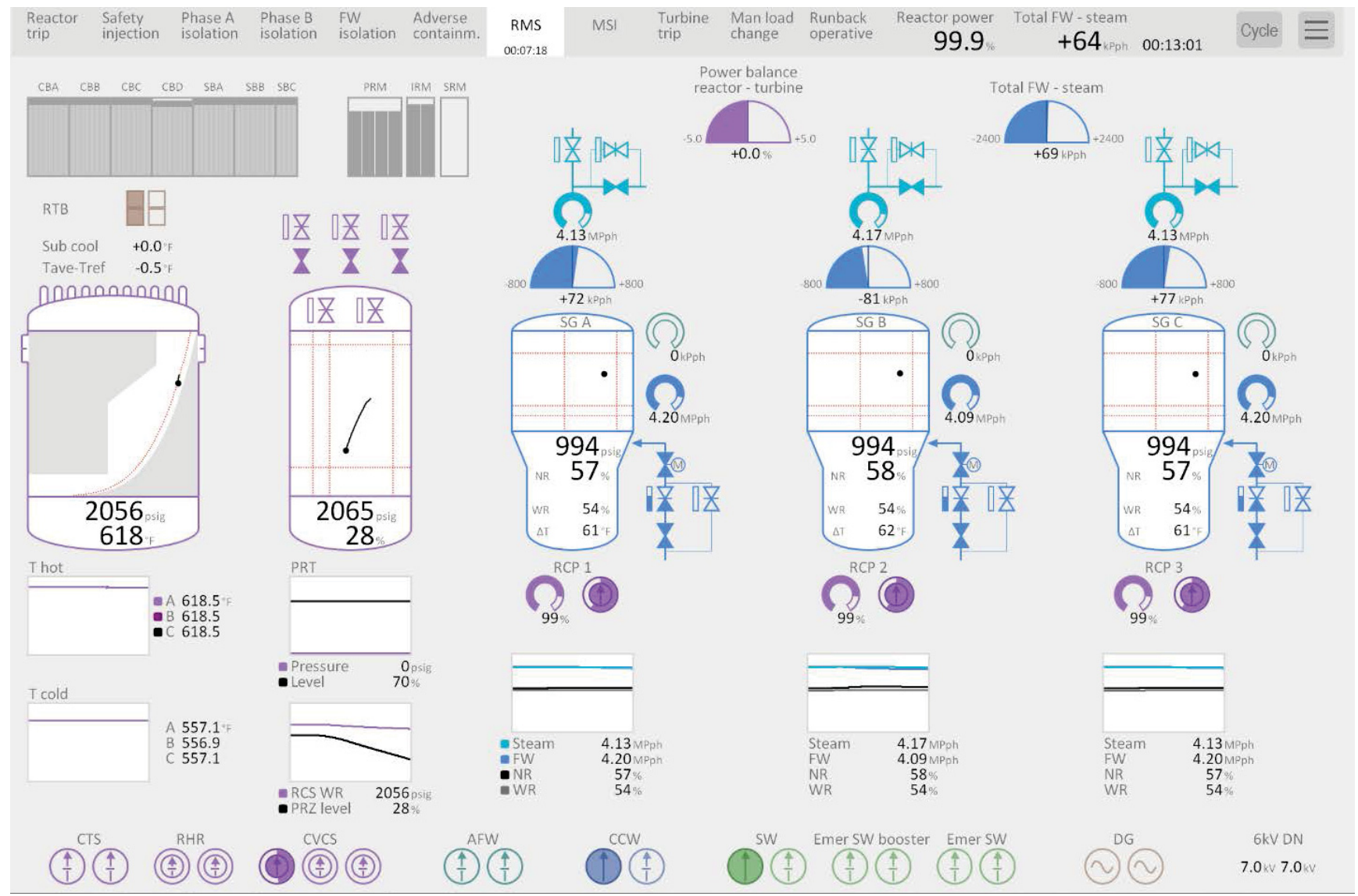

Figure 3 Example of an information integrated display 


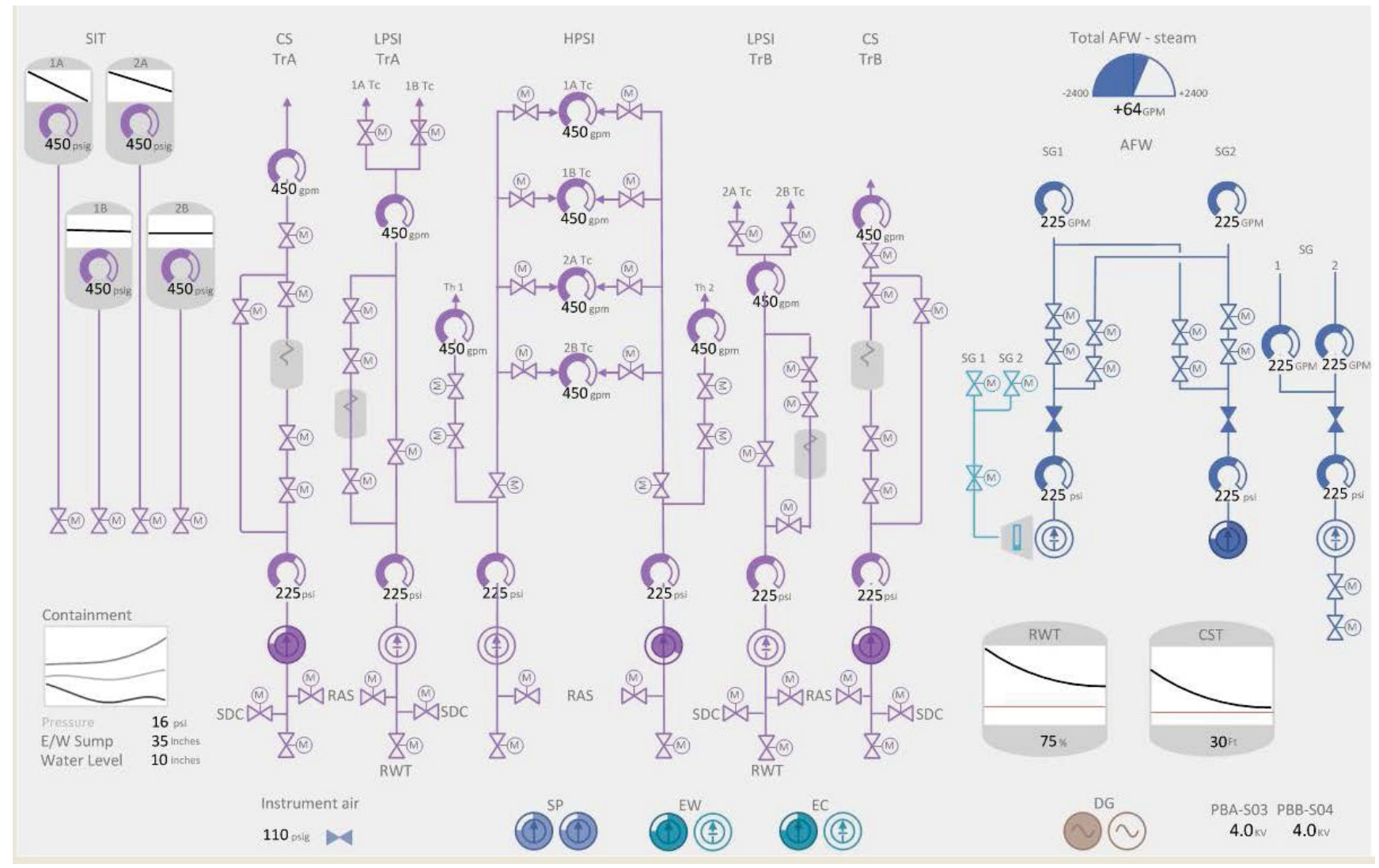

Figure 4 Example of an Emergency Core Cooling display

\section{Testing in simulator environment at INL in the HSSL}

Completing the displays is only the initial step in determining how the end state vision of the control room can support the Operator. The displays need to be tested in an environment similar to the control room to see what the effects of the new displays are. The plant's training simulator is the ideal environment but an unrealistic solution since the digital modifications could take several years to install. An excellent solution is the HSSL at the Idaho National Laboratory. The HSSL is a full scope simulator with a configurable glass top display. The plant's simulator load can be placed on the HSSL's glass top displays and the Overview displays can be effectively placed in the proper position on the control boards. This would provide a realistic view of the final end state vision and allow for the testing of the effectiveness of the newly created Overview displays. This would also allow for any additional testing of changes or newly created displays for the plant going through a modernization project.

The plan would be to run several Operations crews through a minimum of four scenarios based on the plants abnormal operating procedures (AOP) and emergency operation procedures (EOP). The crew will be comprised of a Control Room Supervisor (Senior Reactor Operator) and two Reactor Operators, (one at the reactor controls and one as the balance of the plant operator). A Shift Technical Advisor or Shift Manager could be added in future studies to see if the Overview displays provide additional 
support to these roles in the control room environment. A run plan developed to test the crews with and without the displays will determine if the displays help the crews identify changing plant conditions quicker and more efficiently than they would without the displays. The scenarios will also help in identifying any additional information required in the displays as well as things that are currently in the displays that provide little or no support to the operator and could therefore be removed from the display. Gathering the Operators feedback on the placement and usability of the displays will also help in the iterative process to create the best design to support plant operations in the future.

Developing four scenarios for testing the overview displays requires a person with knowledge in the plants processes and procedures. A good understanding of the plants simulator is also required, to support the scenarios being installed and saved. By having the scenarios saved on the simulator the future crews that attend the study will see identical scenarios and data can be obtained based on the results. Scenarios will focus around the use of the Emergency Operating Procedures (EOPs). Each scenario is expected to last 45 minutes to one hour. We believe the scenarios should require the crew to transition through at least one AOP and two to three EOPs depending on the specific scenario and faults. The goal when designing a scenario is exposing the Operators to familiar tasks and events so they are not overly complex but still challenge the board operators. The tasks and events within the scenarios should focus on those systems and components found on the displays to see if the Operators can quickly identify changes, values, and component status required by the EOPs and AOPs. These scenarios will not be used to grade or evaluate the Operators performance, but are instead used to evaluate the displays and the integrated information.

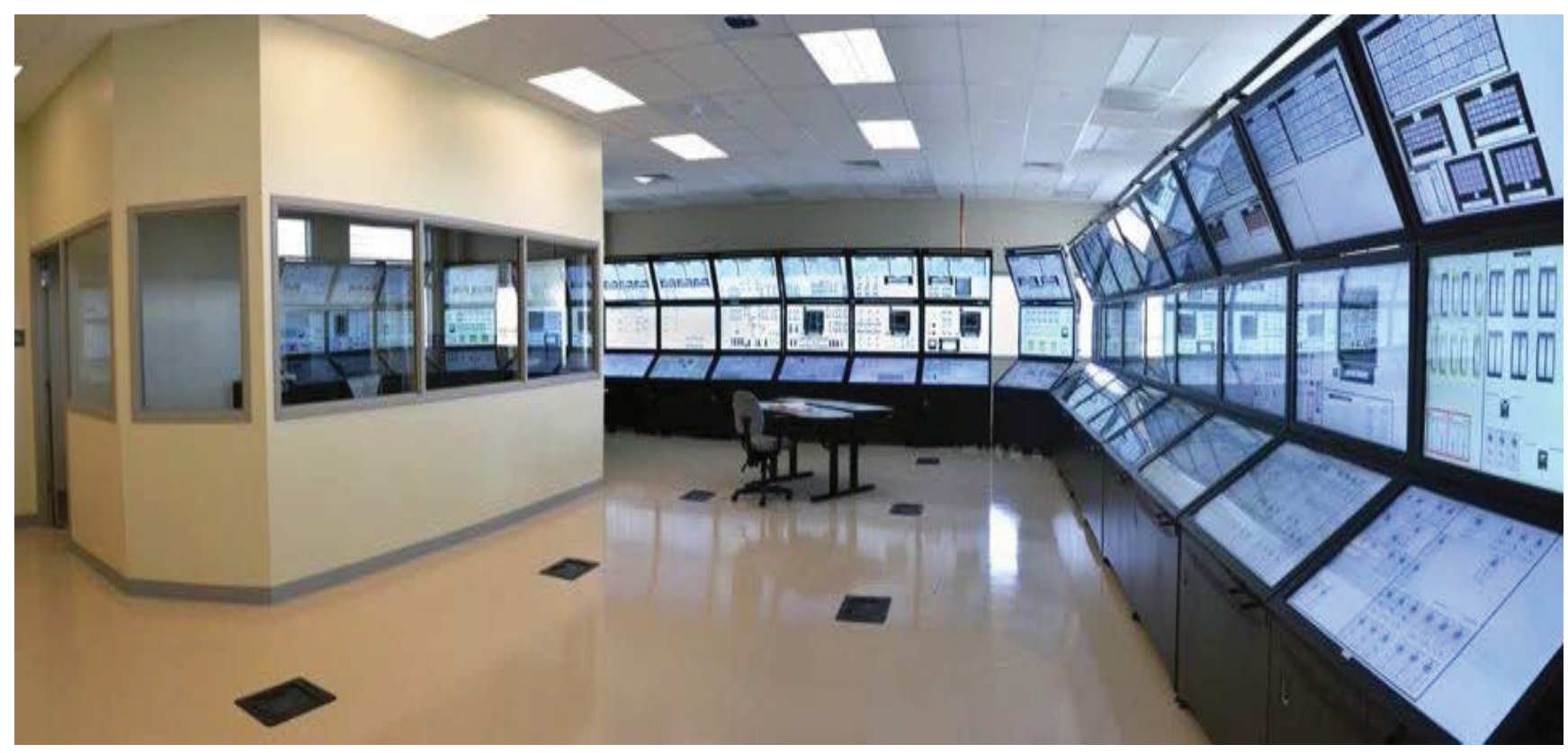

Figure 5 Idaho National Laboratory HSSL 


\section{Use of Micro-Task for Identification of Improved Performance}

The traditional approach for system assessment within the nuclear industry has been to aim for realistic and high fidelity simulations where the control room environment is replicated. In these studies there are a variety of measures from audio and video records to self-rated scales of workload and situation awareness, as well as subjective free or guided process expert assessments on the systems' performance. We think the data from these studies is highly valuable and crucial to the overall assessment of control room performance and safety. Nonetheless, we believe this method require a large effort on resources and result in non-optimal comparison studies, where performance drivers and inhibitors are less controlled and where it is difficult to isolating different contributors to performance.

In this context we argued for the need to develop a method that would be dedicated to situations where we seek a direct comparison of different conditions. The micro task method suits this need by directly targeting different elements or features of the HSIs, enabling the collection of a large amount of data on response times and accuracy. This way we are able to better understand advantages and drawbacks of specific components in the design.

The micro task method is a form of A-B testing applied to detection and decision tasks, currently tested within the MCR context. It is a variation of experimental psychology approach where two or more conditions of a same variable (in this case, the design features/elements) are compared directly, trying to keep all the other variables constant (e.g. same tasks, same information, etc.). In the current applied contexts one should be aware that there might still be confounding variables at play, namely the familiarity and training that the participants have with the innovative versus the conventional displays.

During the trials, the operators are presented with various sequential questions on process status items that might vary from the retrieval of specific values, to the detection or identification of specific components, or even imply decisions on current or future actions. All the presented questions are independent which presents a main advantage: the accuracy of the questions can be independently assessed since the participants can correctly answer any questions regardless of their accuracy in the previous answer; this also allows the randomization of all the questions. This is a unique feature of the method since in scenario-based evaluations the answers/actions taken by the operators often set a context for future actions and decisions and cumulatively contribute to the definition of a resolution path. By having question independence we reduce the subjectivity of the data and avoid the need to analyse highly complex situations that are hard to interpret.

With the micro task method we can then obtain direct measures of performance (accuracy and response time) that can be standardised, replicated, and that might allow the combination of data from different studies, plants, and countries, allowing for an immediate comparison of data. The method allows the collection of large amounts of data in short periods, originating a more effective data collection, analysis, and interpretation. 

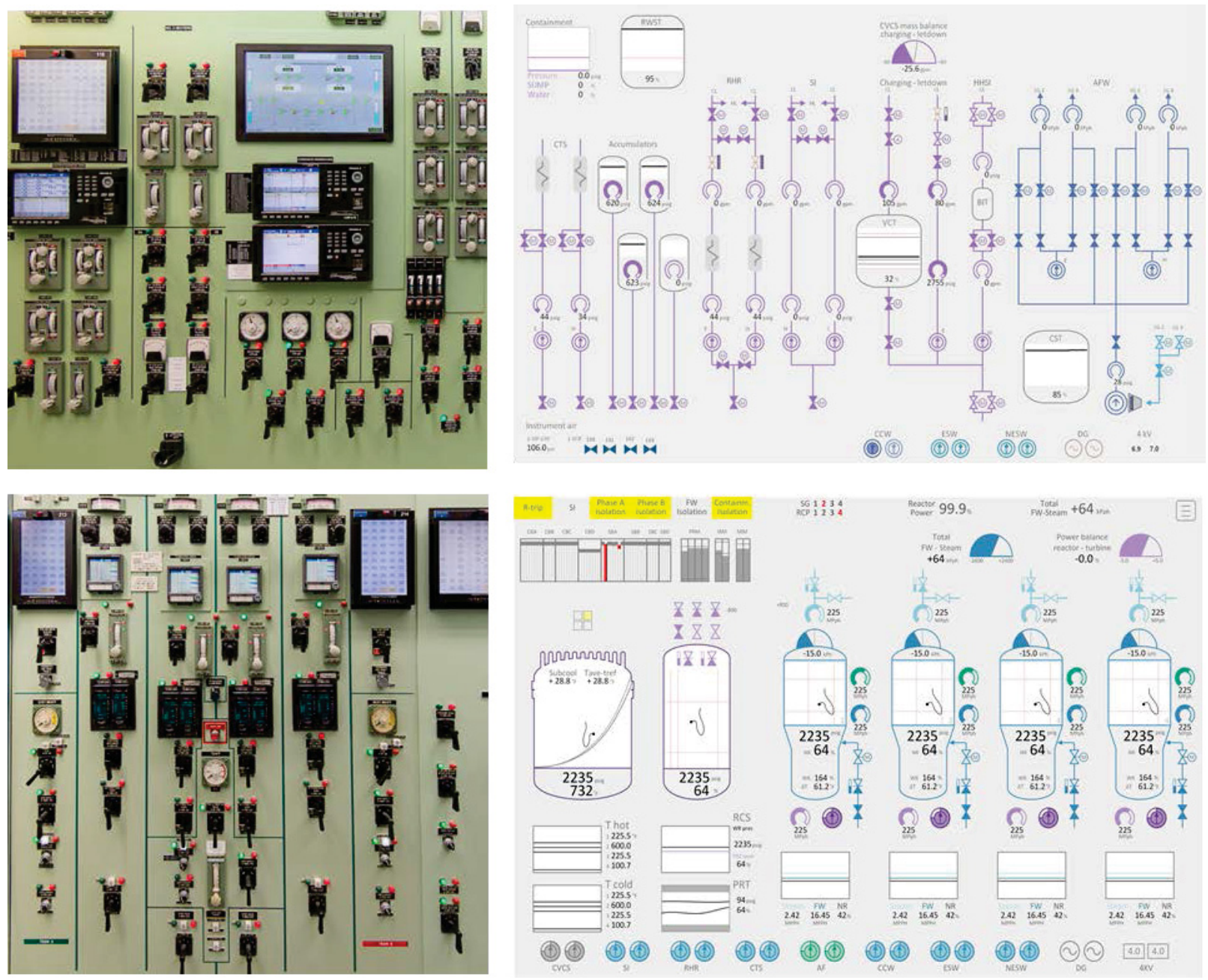

Figure 6 Example of analog (left) and digital (right) control boards for ECCS (top) and RCS (bottom)

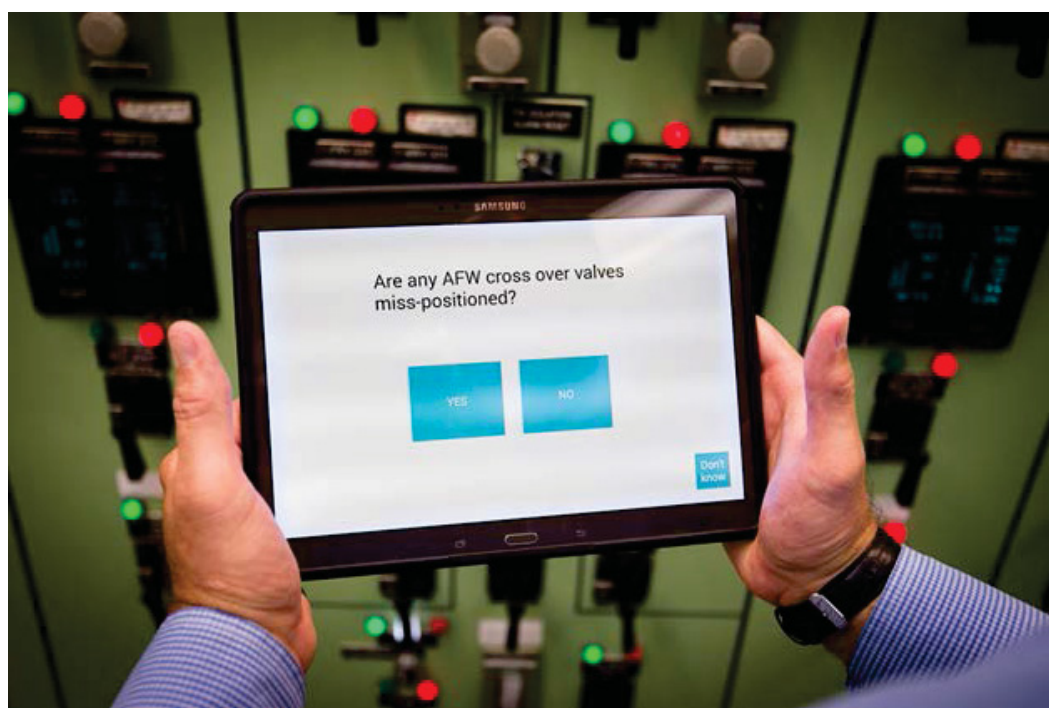

Figure 7 Micro task app in use 


\section{Recommendations for the Digitally Upgraded Control Room}

The future of the legacy nuclear power plants in the US will depend on how they implement the required changes to the main control room control boards. Digital upgrades will be necessary in the very near future and determining both the how and the when will be vital to the success. There are many vendors who will support the plants decision to change out analog technology for digital, but the real question is what to do with the new space available once the old hardware is removed. Current digital technology will have the Operators changing screens to find relevant components, trends and operational information. We at IFE believe based on testing and studies performed that overview displays and task based displays used to support the Operators and supervisors are what is needed when shifting from analog to digital controls. When the control room shifts to a mouse driven process the focus moves away from being at the control board and seeing all the interrelated systems and components, and instead shifts to a single display that focuses on single systems or components. The digital controls then focus the Operator's attention on specific sections of the plant and even specific components. The potential problem this creates is a loss of the ability to easily monitor other systems related to the system being operated. This loss of board awareness can be easily solved by installing high resolution monitors and providing the Operators with complete system and plant overview displays, above and beyond what they see from their operating screens. The when digital upgrades are completed and the Operator workstation will have additional computer screens added, creating a new type of workstation. A new control design may also be a part of the process to allow a more functional and human factored work space. The overall design of the control room must be considered even at the beginning of the modernization project. The first upgrade may not have a significant impact from an operational stand point but the Operator workstation should be included in the initial installation such that future upgrades will not place added undue stress on the Operator and his work process. This is to say if you have upgraded a system and it now requires operation from two different places in the control room (workstation display, and control board) there is a potential to increase the Operators workload instead of reduced it. The addition of the overview displays and the task based displays that are visible from the Operator's workstation means they can have a good visual overview of all systems related to the task being conducted, even if those systems have not been part of a previous digital upgrade. This concept provides the Operator with good plant and situational awareness even as he sits at his digital control station. The displays can be installed on the control boards such that the Operators can see them from the workstation, they can operate equipment and see the resultant effect on the system and the plant. The displays will be designed and human factored for readability from the Operator's workstation. These are the recommendations of IFE on the best way forward to the stepwise concept of digitally upgrading and modernization of an existing nuclear power control room. 


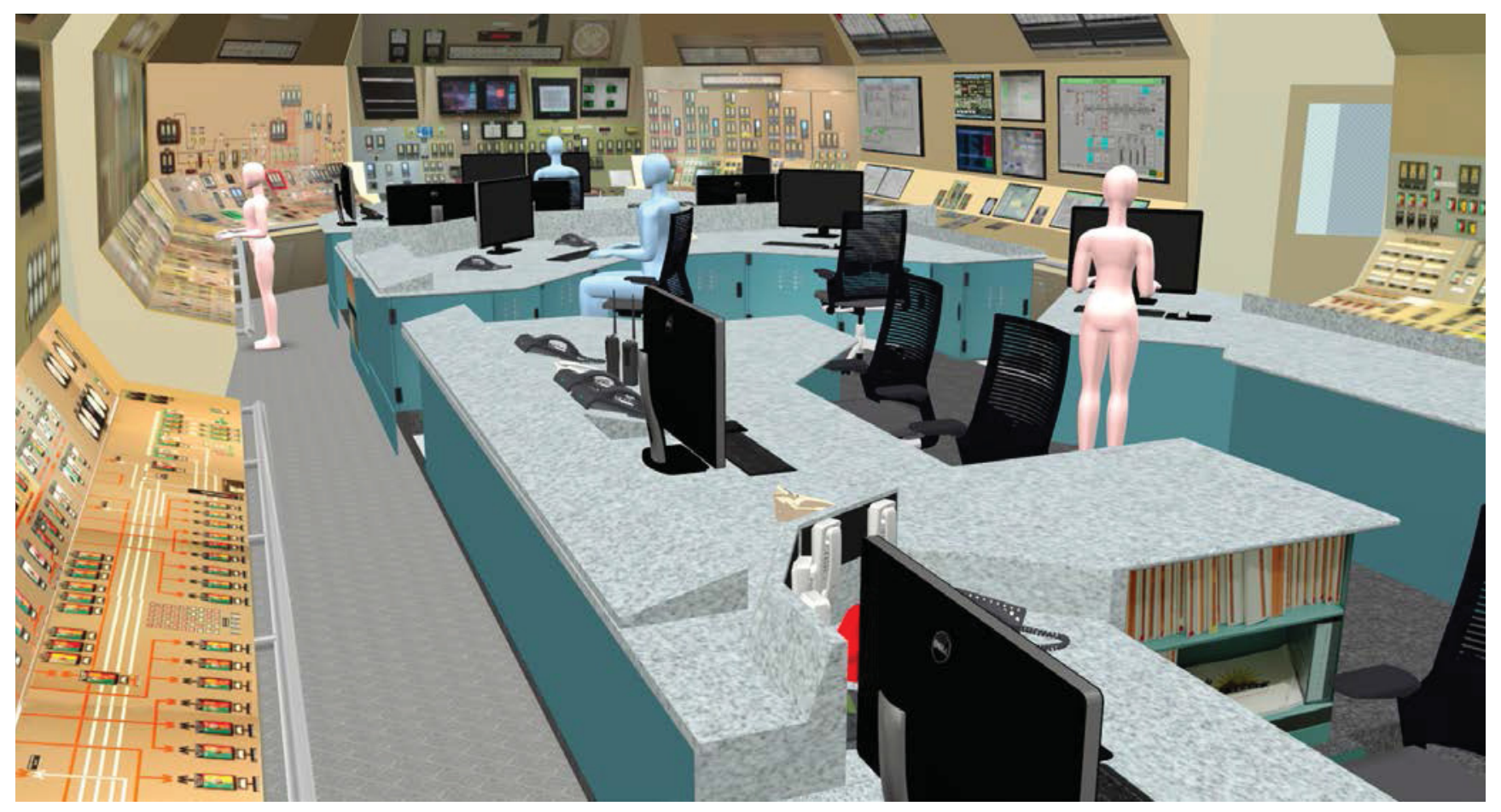

Figure 8 Example of a CREATE drawing of a partial updated Main Control Room (MCR).

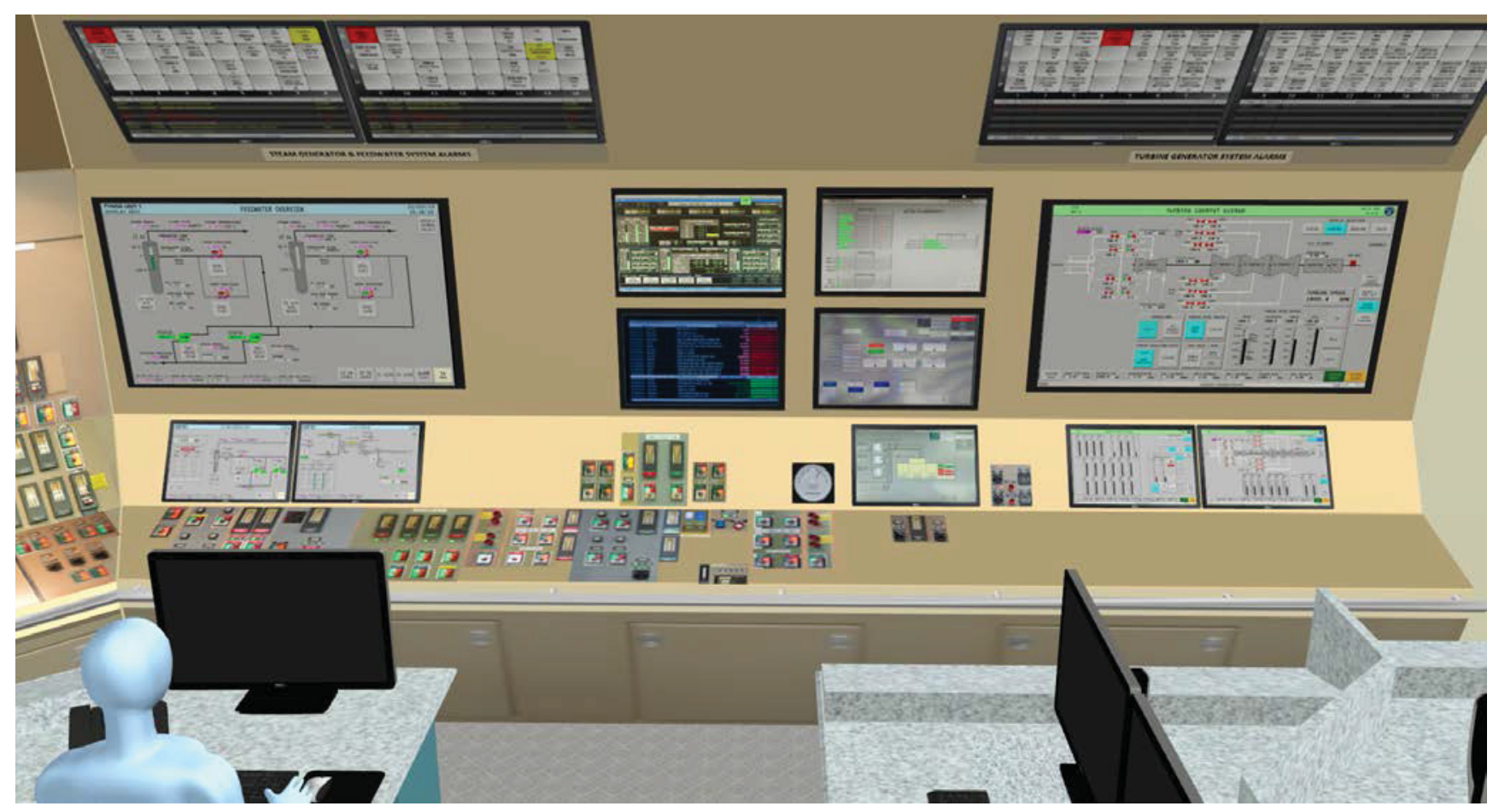

Figure 9 Example of a CREATE drawing of an updated turbine and feed water systems. 